\title{
Le tourisme dans l'empire français. Politiques, pratiques et imaginaires (
}

Paris, Société française d'histoire des outre-mers, 2009, 441 p., bibl.

\section{Anne Doquet}

\section{OpenEdition}

\section{Journals}

Édition électronique

URL : http://journals.openedition.org/etudesafricaines/18061

DOI : 10.4000/etudesafricaines. 18061

ISSN : $1777-5353$

\section{Éditeur}

Éditions de l'EHESS

Édition imprimée

Date de publication : 1 avril 2015

ISSN : 0008-0055

\section{Référence électronique}

Anne Doquet, « Le tourisme dans l'empire français. Politiques, pratiques et imaginaires ( ", Cahiers

d'études africaines [En ligne], 217 | 2015, mis en ligne le 31 mars 2017, consulté le 10 décembre 2020

URL : http://journals.openedition.org/etudesafricaines/18061 ; DOI : https://doi.org/10.4000/

etudesafricaines.18061

Ce document a été généré automatiquement le 10 décembre 2020.

(C) Cahiers d'Études africaines 


\section{Le tourisme dans l'empire français. Politiques, pratiques et imaginaires (}

Paris, Société française d'histoire des outre-mers, 2009, 441 p., bibl.

Anne Doquet

\section{ZYTNICKI, Colette \& KAZDAGHLI, Habib (dir.). - Le tourisme dans l'empire français. Politiques, pratiques et imaginaires ( $x I x^{e}-x x^{e}$ siècles). Paris, Société française d'histoire des outre-mers, 2009, 441 p., bibl.}

1 L'ouvrage Le tourisme dans l'empire français, dirigé par Colette Zytnicki et Habib Kazdaghli, s'interroge sur la mise en tourisme du monde colonial à travers l'analyse, comme l'indique la suite du titre, des politiques, des pratiques et des imaginaires touristiques des $\mathrm{XIX}^{\mathrm{e}}$ et $\mathrm{XX}^{\mathrm{e}}$ siècles. Le sujet est novateur. En effet, bien qu'on assiste en France depuis une quinzaine d'années à la fois à un retour en force de l'histoire coloniale et à une légitimation du tourisme comme objet scientifique (ce dont témoigne le grand nombre de numéros spéciaux de revues consacrés au sujet), le rapport entre tourisme et mouvement impérial n'a été étudié que de manière marginale et c'est toute l'originalité de cet ouvrage de rassembler un ensemble de textes illustrant cette relation et d'en tirer des questionnements inédits réinterrogeant le fait impérial.

Composé de trente et un articles auxquels s'ajoutent l'introduction et le propos conclusif pour un total de 441 pages, le livre est découpé en trois parties selon une option chronologique. La première, «Du voyage au tourisme dans les colonies» (80 pages), s'ouvre par le texte de Lucette Valensi présentant les prémices du tourisme en Tunisie comme l'extension du grand tour, réservé à une élite aristocratique et cultivée. Différents textes suivent ainsi l'émergence du tourisme en Afrique du Nord, mais aussi en Afrique subsaharienne et à La Réunion, faisant apparaître à la fois le rôle du 
colonisateur dans cette expérience, notamment celui des militaires (Arnaud Berthonnet), et la reproduction des modèles existant en Europe, comme l'hivernage ou la visite de sites antiques. La deuxième partie, la plus dense (220 pages), est intitulée "Le tourisme en situation coloniale; propagande, institutions et hommes ". Elle est divisée en trois sous-parties, l'une consacrée aux "Images, propagande et savoirs ", donc aux supports de diffusion touristique ; l'autre appelée "Infrastructures ", portant sur les routes, les stations (balnéaires ou d'altitude) ou la mise en patrimoine des pays colonisés; la dernière consacrée aux "Touristes", touristes français mais aussi catalans, excursionnistes (Daniel Norman) mais aussi touristes militants (Sylvain Pattieu) ou encore mutins, "touristes malgré eux " (Rémy Pech). La troisième partie traite enfin «du tourisme colonial au tourisme contemporain », avec une série de six textes examinant les héritages touristiques de la colonisation, qu'ils soient toujours largement guidés par la France, comme dans le cas du tourisme montagnard au Maroc (Hassan Ramou) ou impulsés localement comme dans la cuisine réunionnaise (Laurence Tibère).

«Un outil de domination colonial?». Faisant écho à certains écrits classiques dénonçant le tourisme en tant que forme de néo-colonisation, le sous-titre du livre pourrait laisser présager un accent postcolonial de ses textes. L'ouvrage ne peut en fait s'y résumer, la trentaine d'articles le constituant présentant une forte hétérogénéité tant thématique que paradigmatique. Dans leur introduction, les coordinateurs rappellent que l'activité touristique et l'impérialisme sont «les produits d'un même contexte» (p. 7) et "passent par la prise de possession d'un territoire et son exploitation » (p. 8). Intégré dans la machinerie administrative coloniale même si des initiatives privées en sont souvent à l'origine, il est un "instrument, pensé, voulu comme tel, de la domination» (p. 13). Mais ils notent aussi que les réalités ne furent souvent pas à la hauteur des ambitions politiques et que des contestations ont pu apparaître conjointement de la part les populations colonisées et des sociétés coloniales locales elles-mêmes, comme l'illustre de façon éclairante le cas de la mise en patrimoine de Tripoli face à l'autorité fasciste de l'Italie (François Dumasy). Des tentatives de créer un autre tourisme au parti pris anticolonialiste ont également vu le jour au travers d'associations (Sylvain Pattieu). Il reste néanmoins évident que les visées expansionnistes de l'administration ont tracé les voies du tourisme. Expansionnisme territorial tout d'abord: plusieurs articles examinent le rôle des militaires en tant que pionniers dans le développement touristique, notamment dans les régions sahariennes. Partout, le quadrillage du territoire par des routes tracées au profit de l'armée a délimité les trajets touristiques, mais parfois l'aménagement des voies empruntées par les visiteurs a été privilégié sans arguments militaires (Serge La Barbera). Expansionnisme idéologique ensuite, dans la mesure où la France devait absolument apparaître dans les territoires colonisés que ce soit de façon métaphorique, par exemple à travers la réhabilitation du patrimoine archéologique romain en Tunisie comme symbole de l'action impériale française (Myriam Bacha, Naïm Ghali) ou à travers la revalorisation du patrimoine islamique nord-africain permettant une conjonction possible de la francité et de l'islamité en Algérie (Alain Messaoudi), ou de manière plus concrète à travers une "re-création" d'espaces typiquement français pour les « récréations » des colons au Vietnam et la garantie qu'ils restent sur place (Emmanuel Peyvel). Divers textes attestent de ces espaces de regroupements francofrançais, notamment dans le tourisme sportif générant un "entre-soi mondain entre gentlemen-amateurs » (Évelyne Combeau-Mari, Denis Voituret) et l'article de Sophie 
Dulucq, consacré au développement du tourisme au sud du Sahara, exprime bien la sociabilité « blanche » et « coloniale » dont témoignent les récits de l'époque (p. 65).

Qu'en est-il donc du rapport visiteur/visité, souvent au cœur de l'analyse du tourisme? Peu de contributions en donnent des indices. Celles abordant les ambitions patrimoniales de l'administration élucident sa volonté d'archaïser les sociétés colonisées pour mieux glorifier la modernité des dominants et légitimer l'Empire. Les touristes en sont-ils des complices passifs n'affichant que mépris pour les populations locales, tels les mutins, "touristes malgré eux» du texte de Rémy Pech? Les nombreuses contributions consacrées à la mise en tourisme du désert saharien montrent que les populations locales ne constituent peut-être pas le centre de leurs préoccupations, le tourisme y étant largement imaginaire et l'importance du voyage colonial touristique résidant davantage dans son récit que dans la réalité (Alison $\mathrm{J}$. Murray Levine). Les clichés sur les populations peuvent ainsi être aisément charriés par le tourisme, tel celui de la femme orientale et de son érotisme (Driss Boumeggouti). Il faut noter par ailleurs une variété de pratiques et de représentations due à la diversité des touristes eux-mêmes, comme le précise le texte de Geneviève Falgas en Tunisie, où apparaissent une clientèle extérieure de classe internationale, une clientèle extérieure et intérieure dite "touristique», une autre dite "populaire», et qui rappelle que les touristes pouvaient aussi être des Tunisiens. Cette clientèle locale interroge la place des colonisés dans la construction du tourisme. Les initiatives de l'administration en matière de tourisme n'ont pu se faire sans des relais locaux dont on peut que regretter le peu de place qu'y consacrent les différentes contributions. De même, les textes de la troisième partie du livre, consacrés aux héritages de la colonisation en matière de tourisme, laissent un peu le lecteur sur sa faim. Si on y voit les Réunionnais jouer de ce passé en faisant goûter au touriste le plat des esclaves, la plupart des articles mettent l'accent sur les continuités, notamment au niveau des infrastructures, là où on attendrait une analyse plus précise des tensions entre le poids de cet héritage, notamment idéologique, et l'expression d'identités renouvelées produites par les États naissants.

5 C'est sans doute cette grande diversité d'acteurs, de situations, mais aussi d'époques qui rend parfois difficile une mise en lien des différents textes constituant l'ouvrage. Ceuxci s'avèrent largement inégaux, un certain nombre s'arrêtant au niveau de la description sans se saisir de la problématique fondamentale du livre. L'origine disciplinaire des auteurs reste par ailleurs absente. Certains thèmes n'apparaissent qu'en filigrane, tandis que d'autres se font répétitifs au fil des textes (sur le Maghreb) et la catégorie-même de touriste prend des acceptions diverses parfois déroutantes pour le lecteur. Le choix d'une présentation des textes selon un ordre chronologique au détriment d'un découpage thématique n'était ainsi peut-être pas le plus judicieux. Mais cette disparité est en partie atténuée par l'épaisseur théorique de l'introduction, qui offre une synthèse argumentée et pédagogique sur les liens entre activités touristiques et domination coloniale même si elle souffre d'un manque de bibliographie générale. L'ouvrage pâtit inéluctablement d'un déséquilibre géographique : vingt-cinq des trente et un articles traitent du Maghreb ou du désert saharien. Son origine, un programme de recherche franco-tunisien et une journée d'étude consacrée au tourisme dans les trois pays du Maghreb colonisés par la France, en a largement déterminé le contenu. Néanmoins les quelques textes qui font figure d'exception à cette focalisation géographique (sur La Réunion, le Proche-Orient, le Vietnam et l'Afrique subsaharienne) suffisent à prouver que le sujet mérite d'être étendu. Dans la même logique, si la grande 
majorité des contributions portent sur la domination coloniale française, les textes sur le tourisme au «Maroc espagnol» (Valero Alet) ou celui de Tripoli sous domination italienne illustrent cette même propension au comparatisme. L'ensemble des articles exprime le même volontarisme des autorités coloniales en matière d'aménagement touristique, illustrant la manière dont l'administration a fait du tourisme un instrument politique et économique et l'un de ses rouages (p. 11). En ce sens, ce livre a le mérite de poser de nouvelles et importantes questions, même si ses contributions y répondent de manière inégale, et de poser les jalons d'une recherche approfondie et comparative sur l'étroitesse des liens entre le tourisme et le colonialisme. 